\title{
ROSETTA LANDER BATTERIES EXPERIENCE DURING ALL OPERATION PHASES
}

\author{
Céline Cénac-Morthé $^{(1)}$, Laurence Mélac ${ }^{(1)}$, Stephane Fredon ${ }^{(1)}$, Laurène Gillot ${ }^{(1)}$, Philippe Gaudon ${ }^{(1)}$, Michael \\ Maibaum $^{(2)}$, Barbara Cozzoni ${ }^{(2)}$, Valentina Lommatsch ${ }^{(2)}$, Koen Geurts ${ }^{(2)}$, Paul Brochard ${ }^{(3)}$, Alex Clark ${ }^{(4)}$ \\ (1) Centre National d'Etudes Spatiales, Toulouse, France, Celine.Cenac-Morthe@cnes.fr \\ (2) Deutsches Zentrum für Luft- und Raumfahrt, Cologne, Germany, Michael.Maibaum@dlr.de \\ ${ }^{(3)}$ Saft, Poitiers, France, Paul.BROCHARD@saftbatteries.com \\ (4) ABSL, Abingdon, United Kingdom, alex.clarke@absl.enersys.com
}

\begin{abstract}
Rosetta is an ambitious ESA mission, launched in March 2004 from Kourou and which performed a rendezvous with comet 67/P Churyumov-Gerasimenko. Its lander, Philae, achieved landing on comet soil on the $12^{\text {th }}$ November 2014 and performed 64 hours of science activities on its batteries before going into hibernation due to lack of solar energy.

Philae is operated by the Lander Control Centre (LCC) at DLR Cologne Germany and the Science Operations and Navigation Centre (SONC) at CNES Toulouse France. The Lander system was provided by a European consortium (Germany, France, Italy, Hungary, Finland, UK, Ireland, Switzerland and Austria) and supports a scientific payload of 10 instruments.

The Philae battery system was provided by CNES, it is composed of a Saft primary battery $(1518 \mathrm{Wh})$ and an ABSL secondary battery $(151 \mathrm{Wh})$. The primary is made of non-rechargeable LSH20 $\left(\mathrm{LiSOCl}_{2}\right)$ Saft cells and the secondary of rechargeable ABSL Li-ion $18650 \mathrm{HC}$.

For the Philae mission, the energetic constraint was very important. Indeed, before launch, the operations had to be planned considering variability of several parameters (descent duration, communication slots, comet temperature, solar power availability, etc.). Since Rosetta launch, cells and batteries have been stored and specific ground test plans have been identified in order to follow the battery ageing and to validate the final Philae operation schedule. From ground test results, an electrical model of the batteries was developed to help the operations scheduling.

During cruise, the operations consisted of secondary batteries monitoring and tests and primary battery conditioning. During separation and on-comet operations, the behaviour of the batteries system was checked and electric simulations helped with activities scheduling.

Firstly, this paper will describe the Philae mission. In a second part, the batteries system will be presented. The ground strategy will be detailed. Finally, the operations of Philae batteries system will be described.
\end{abstract}

\section{ROSETTA LANDER: PHILAE}

Rosetta is an ESA mission launched in March 2004, with the objective to study the comet $67 \mathrm{P} / \mathrm{Churyumov}$ Gerasimenko. The space probe, Rosetta, is composed of several payloads, particularly, Philae, the lander, [1]. After 10 years of cruise phase, the last three of them in hibernation, Philae was switched on again in March 2014. The Philae's Separation, Descent and Landing (SDL) on the comet occurred in November 2014. During three days, different science measurements were realised, exploiting the energy stored in the batteries. This operational phase is called First Science Sequence (FSS). After this phase, a Long Term Science phase (LTS) should have started. Due to landing conditions with respect to illumination, it happened only after 7 months of hibernation, [2].

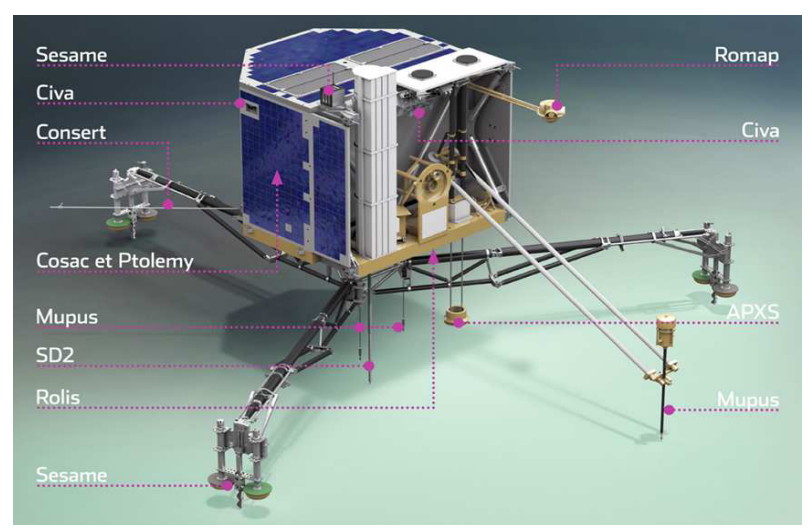

Figure 1. View of Philae and instruments on board

The Philae lander was designed by a European consortium under the leadership of DLR Cologne (German aerospace centre). It weighs about $100 \mathrm{~kg}$ and includes ten instruments. Philae power was supplied through an umbilical line to the Rosetta probe during the cruise phase and by solar panel with Maximum Power Point Trackers (MPPT) and the batteries system during SDL and on-comet phases. The batteries system provided by CNES will be detailed.

\section{BATTERIES SYSTEM}

The batteries system is composed of a primary battery and a secondary battery (Figure 2). 


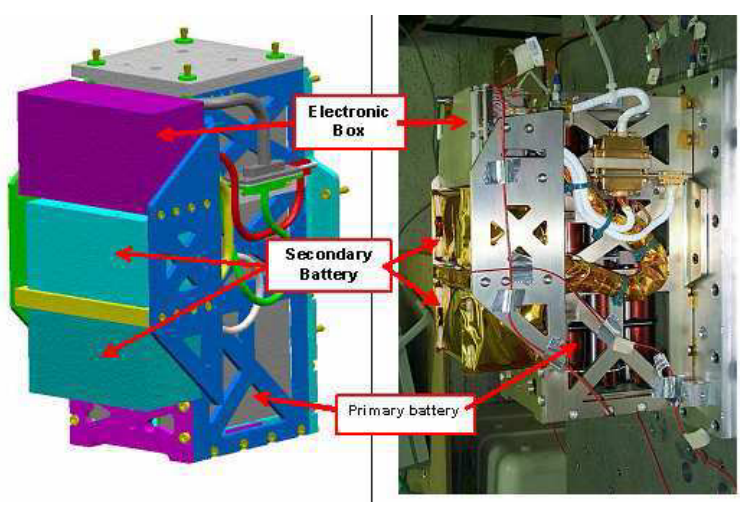

Figure 2. Batteries system

\subsection{The primary battery}

The primary battery is equipped with LSH20 cells manufactured by Saft (LiSOCl2). The configuration of the battery is 4 strings with 8 cells in series $(8 s 4 p)$. The nominal capacity at BOL (Beginning Of Life) is $52 \mathrm{Ah}$ (on $240 \Omega / 15 \mathrm{~mA}$, at $20^{\circ} \mathrm{C}$ for $2 \mathrm{~V}$ cut-off voltage). The open circuit voltage is $29.36 \mathrm{~V}$ at $20^{\circ} \mathrm{C}$. The range of storage temperatures is $\left[-60^{\circ} \mathrm{C} ;+85^{\circ} \mathrm{C}\right]$. The range of operational temperatures is $\left[-30^{\circ} \mathrm{C} ;+60^{\circ} \mathrm{C}\right]$. A depassivation circuit is implemented in order to impose discharge current pulses and to break the passivation layer that was formed during storage. Moreover, it shows the voltage of each string.

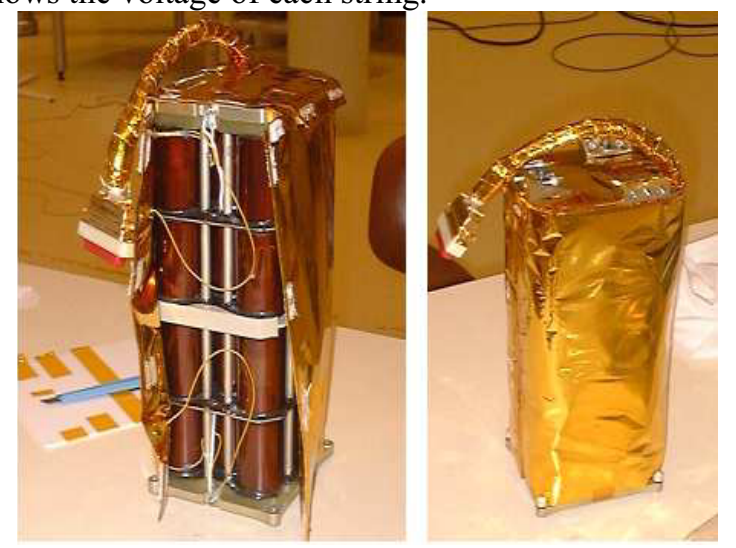

Figure 3. Philae primary battery (Saft)

\subsection{The secondary battery}

The secondary battery is manufactured by ABSL with Sony $18650 \mathrm{HC}$ cells. There are two blocks of these. The configuration of the first block is $2 \mathrm{p} 7 \mathrm{~s}$ and of the second block is $7 \mathrm{~s} 2 \mathrm{p}$. The second block had to be added later in the design phase, therefore its configuration is different. A monitoring circuit is connected to block 1. It ensures the monitoring of cell-pair voltages, the high and low voltage detections and the cell balancing.

Each battery is equipped with thermistors and heaters to ensure thermal control.

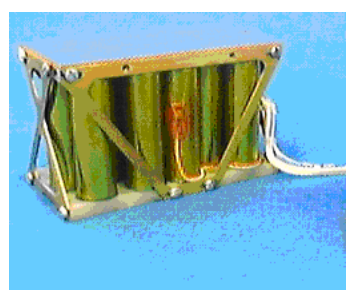

Figure 4. One block of Philae secondary battery (ABSL)

\section{GROUND STRATEGY}

Different ground activities were realised during the mission cruise phase in order to:

- Check that the primary battery cells are in good health, which can only be realized on ground.

- Prepare the operations during SDL and on-comet phase [3].

\subsection{Ground tests}

Concerning the primary battery, a storage strategy was organised. The storage conditions on ground change as a function of flight conditions (temperature, durations) to be the most representative on ground of the flight cell life.

Every two years, a few stored cells were discharged to verify their health. These tests consisted in a first depassivation followed by a capacity measurement on six cells. The results showed that after fifteen discharge pulses, the cell voltages reached their nominal value (between $3.2 \mathrm{~V}$ and $3.3 \mathrm{~V}$ ) for the $0.85 \mathrm{~A}$ discharge current at $20^{\circ} \mathrm{C}$. Moreover, the measured capacity is around 9Ah (under the discharge current: 0.2A; temperature: $20^{\circ} \mathrm{C}$; End Of Charge Voltage: $2 \mathrm{~V}$ ). Since the beginning of the test ( 6 years), the loss of capacity has been inferior to $1 \%$.

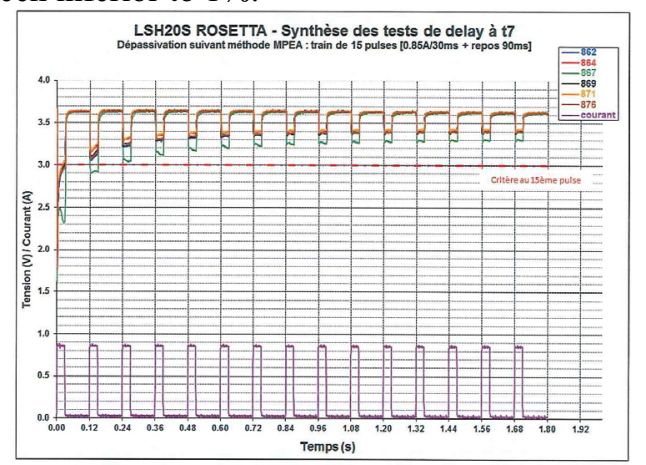

Figure 5. Depassivation test on several stored LSH2O cells - Saft data

Moreover, in order to define the maximum power discharge pulse allowed during landing without turning off the lander, different power pulses were imposed and cell voltages were measured. Finally, before landing, a typical discharge profile of the mission was imposed on a spare battery to ensure that the power peak during landing would not lead to a too low bus voltage (condition of lander switch off) and to evaluate the 
available energy.

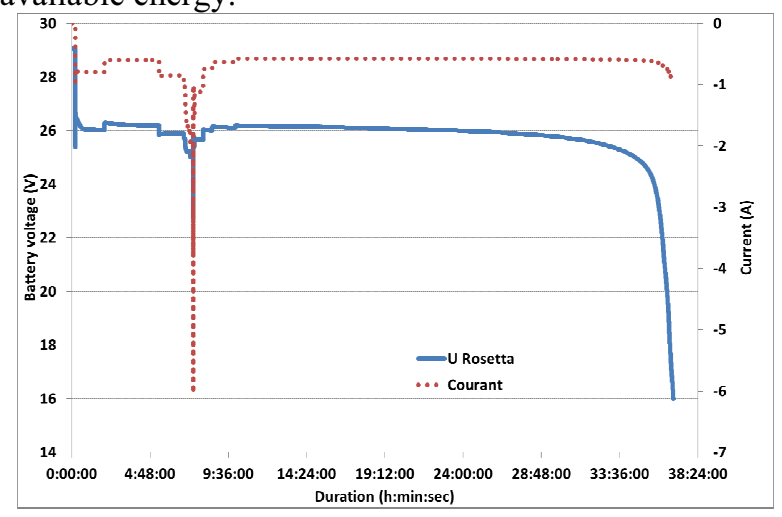

Figure 6. Typical discharge profile test on $8 s 3 p$ battery

The tests on secondary cells allowed to define their behaviour in severe temperature conditions $\left[-40^{\circ} \mathrm{C}\right.$; $\left.+40^{\circ} \mathrm{C}\right]$ and discharge conditions $[\mathrm{C} / 10 ; \mathrm{C} / 2.5]$.

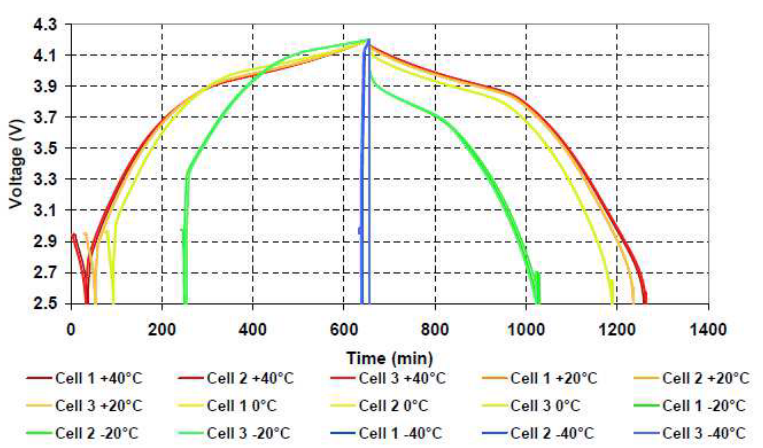

Figure 7. Capacity measurements on $18650 H C-A B S L$ data

\subsection{Model}

From the different test results, the batteries system was modelled to define the available energy at separation and the bus voltage to prepare the operations [7].

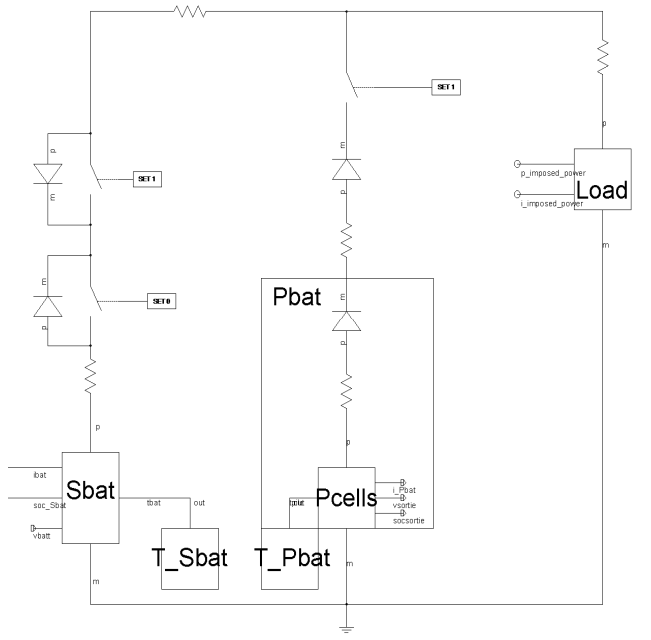

Figure 8. Batteries system model

Each battery was modelled from an equivalent electrical circuit:

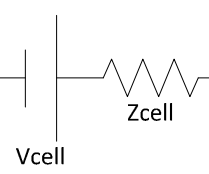

Figure 9. Equivalent electrical circuit used for each battery model

The different components were modelled from the data of battery manufacturers. They are expressed in function of temperature, state of charge and/or open circuit voltage.

Initially, each battery was modelled and validated separately. For the primary battery, the different ground tests indicated previously were used to realize the validation of cells and battery models. For example, the typical discharge presented on Figure 6, was simulated with the primary battery model. The results were shown on Figure 10. The voltage errors, expressed in percent, between simulation and test results were equal to $-1.3 \%$ during $15 \mathrm{~W}$ discharge power and $+0.12 \%$ during $140 \mathrm{~W}$ discharge power peak. The capacity error, expressed in percent, between simulation and test results were equal to $1 \%$.

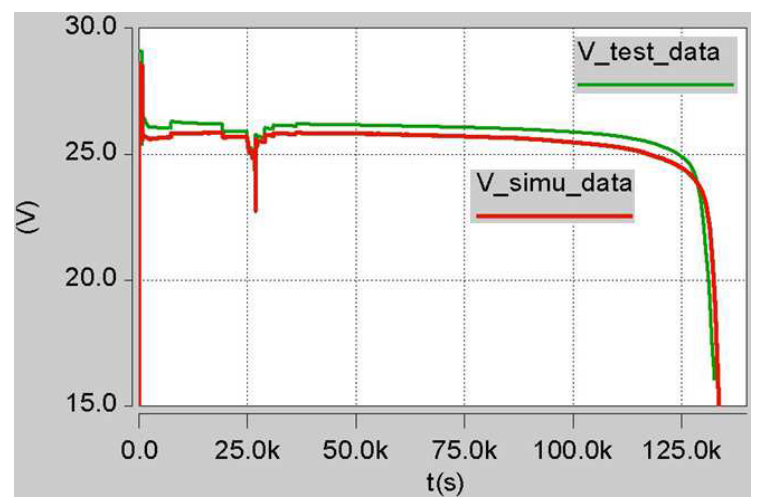

Figure 10. Comparison of primary battery simulation results with the test results of typical discharge profile

The model of secondary battery was always used for CNES Myriade satellites and validated from telemetries, as described in [5].

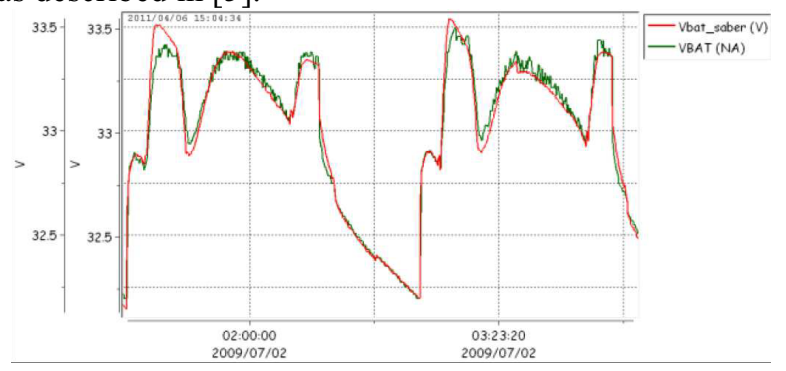

No ground or flight tests allowed validating the batteries system model. In the model, the values of harness resistances were defined from the cable types and from the length of harness. The ones of diode resistances and diode voltage drops were defined from manufacturers' 
datasheet.

Thanks to the batteries system model, a dedicated operational loop was prepared as illustrated in Figure 11.

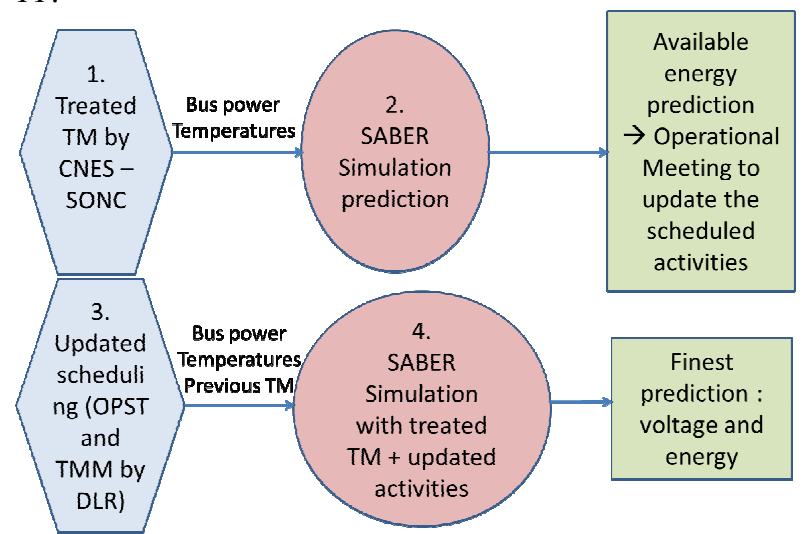

Figure 11. Operational loop used for the prediction of available energy

The objective was to integrate telemetry in the model and provisional power consumption in order to predict in real time the energy available in the batteries and support the scheduling of activities during on-comet operations. The telemetries were downloaded and treated in order to be used on the batteries system model. A first prediction of available energy was given to lander team. The lander team (DLR/SONC) in accordance with the scientists, updated the scheduling of activities and gave us the new power profile. This last one was integrated with telemetries to give a finest prediction of available energy and bus voltage. The data of bus voltage was used to define the switching off of the lander.

\section{OPERATIONS}

As presented previously, the Philae mission was divided into several phases: cruise and post-hibernation, SDL, FSS and LTS. For each phase, the batteries operations will be detailed.

\subsection{Cruise}

During cruise, the state of charge of the secondary battery was monitored regularly thanks to the battery voltage measurement. An unexpected decrease in state of charge was detected. So, the secondary battery was charged regularly in order to avoid under-discharge, particularly during the hibernation phase, see Figure 12 . In addition to this, some tests of the power system were realised, like the charge of batteries through Philae power subsystem.

The operations of conditioning of the primary battery began at Philae wake-up. It consisted in several depassivations to ensure a sufficient voltage of the primary battery at the beginning of SDL. After ten years without any discharge, the first voltage at cell level is around $2.43 \mathrm{~V}(19.419 \mathrm{~V} / 8)$ at low temperature $\left(3^{\circ} \mathrm{C}\right)$, see Table 1. After 6 months without any discharge, the first voltage at cell level is around $3.12 \mathrm{~V}(24.970 / 8)$ at $10^{\circ} \mathrm{C}$.

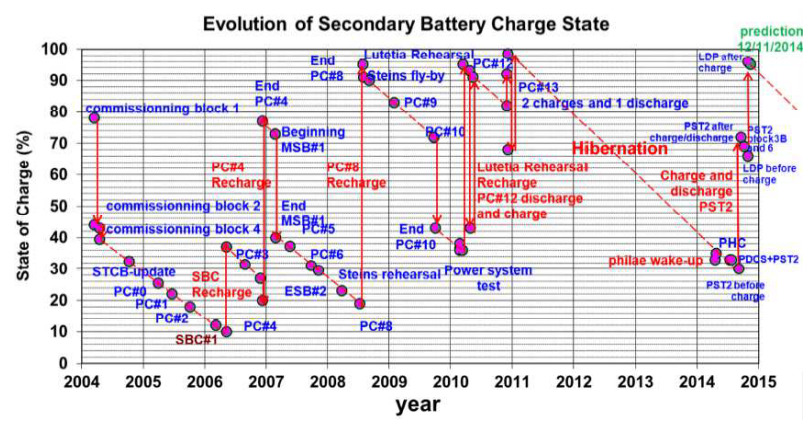

Figure 12. Evolution of secondary state of charge state during cruise

\begin{tabular}{|c|c|c|c|}
\hline & $\begin{array}{l}\text { March } \\
2004 \\
\end{array}$ & $\begin{array}{l}\text { April } \\
2014 \\
\end{array}$ & $\begin{array}{l}\text { October } \\
2014 \\
\end{array}$ \\
\hline Storage condition & $<-30^{\circ} \mathrm{C}$ & $<-40^{\circ} \mathrm{C}$ & $<-40^{\circ} \mathrm{C}$ \\
\hline Test temperature & $10^{\circ} \mathrm{C}$ & $3^{\circ} \mathrm{C}$ & $11.5^{\circ} \mathrm{C}$ \\
\hline $\begin{array}{l}1^{\text {st }} \text { measurement : } \\
\text { string } 1 \text { voltage } \\
\text { after } 15 \mathrm{~ms} \\
\text { depassivation }\end{array}$ & $21.3 \mathrm{~V}$ & $19.419 \mathrm{~V}$ & $24.970 \mathrm{~V}$ \\
\hline $\begin{array}{lcc}\text { string } 4 & \text { voltage } \\
\text { after } 485 \mathrm{~ms} \text { of } \\
\text { depassivation }\end{array}$ & $25.9 \mathrm{~V}$ & $25.657 \mathrm{~V}$ & $26.152 \mathrm{~V}$ \\
\hline $\begin{array}{l}\text { Last measurement } \\
: \text { string } 4 \text { after } \\
4785 \mathrm{~ms}\end{array}$ & NA & $25.84 \mathrm{~V}$ & $26.170 \mathrm{~V}$ \\
\hline $\begin{array}{l}\text { Max voltage } \\
\text { difference between } \\
\text { strings on the } 5^{\text {th }} \\
\text { cycle }\end{array}$ & $0.23 \mathrm{~V}$ & $0.549 \mathrm{~V}$ & $0.449 \mathrm{~V}$ \\
\hline $\begin{array}{l}\text { Max voltage } \\
\text { difference between } \\
\text { strings on the } 40^{\text {th }} \\
\text { cycle }\end{array}$ & NA & $0.503 \mathrm{~V}$ & $0.485 \mathrm{~V}$ \\
\hline
\end{tabular}

Table 1. Synthesis of the different depassivations realised during cruise

\subsection{SDL/FSS}

SDL and the first part of FSS were scheduled on an automatic block. Some simulations were performed to ensure that the power peak during touch-down would not induce a decrease of voltage too great and trigger the lander switch-off, see Figure 13. 


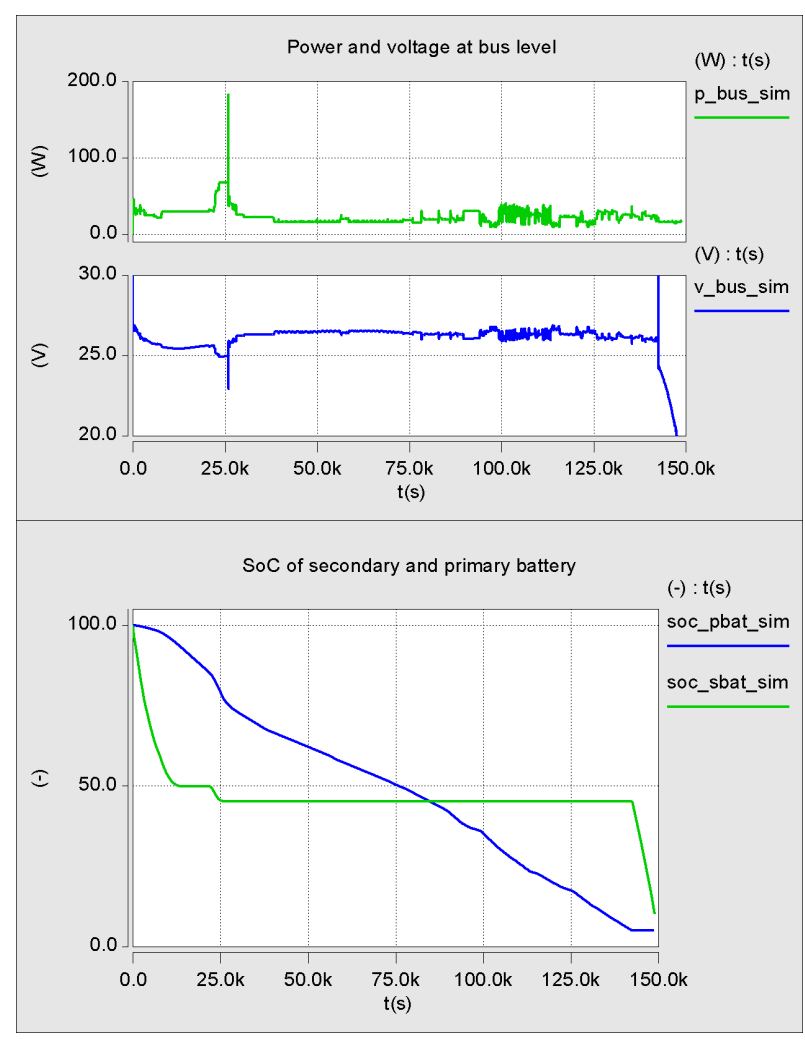

Figure 13. Simulation results dedicated to SDL/FSS first operations

The telemetry received during the first Rosetta-Philae visibility slot after separation indicated that the batteries system behaviour was nominal. Indeed, bus voltage was around $27.20 \mathrm{~V}$ just after connection. Both primary and secondary batteries are giving current to the bus $($ I_PBATT $=429,45 \mathrm{~mA}$ and I_SBATT $=487,6 \mathrm{~mA})$. The temperatures were in the expected range: $26^{\circ} \mathrm{C}$ for the primary battery and $16^{\circ} \mathrm{C}$ for the secondary battery. The solar arrays provided energy during all descent phase which permitted to have a lower discharge current on the battery.

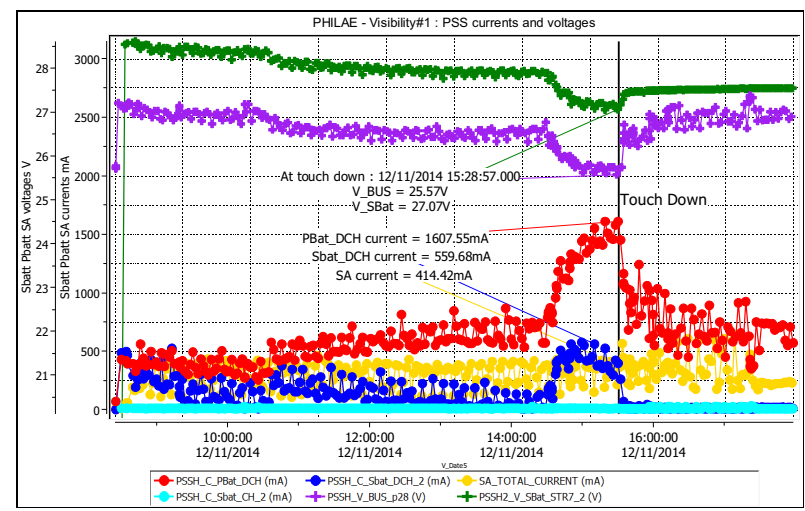

Figure 14. Batteries system telemetries during visi\#1 (green : secondary battery voltage, purple: bus voltage, red : primary battery current, blue : secondary battery discharge current, yellow: total solar arrays current)
Through the solar array currents, the spin rotation of the lander and its stabilisation were observed, indicating the non-nominal touch-down of Philae in the target landing site Agilkia and a final resting landing in Abydos.

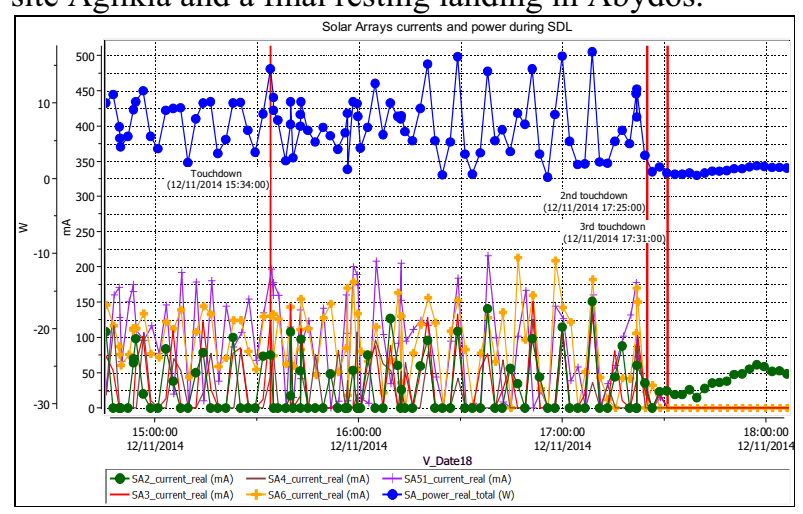

Figure 15. Solar arrays currents and power during $S D L$ (green: current of $S A n^{\circ}$, purple: currents of $S A n^{\circ} 1$ and 5, red: current of $S A n^{\circ} 3$, blue: $S A$ total power, yellow: current of $S A n^{\circ} 6$, brown: current of $S A n^{\circ} 4$ )

In order to understand the situation, the foreseen activities (movement/deployment) in the second visibility were postponed and the execution of science measurements not requiring any mechanical activities was chosen. So, the power consumption was reduced. As expected thanks to simulation, the lander energy was mainly provided by the primary battery, see Figure 18 .

After the second visibility, some simulations were realised using telemetry and estimated power consumption, see Figure 16. The results indicated that the lander should go into standby mode two hours before the start of the fifth visibility.

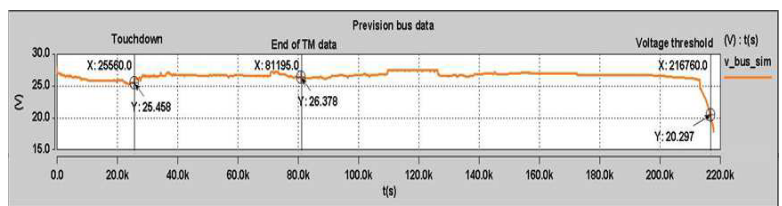

Figure 16. Prediction after the second visibility. Lander standby mode at 2014/11/14 20:37 UTC while VISI\#5 is at 22:30 UTC

So, for the third and fourth visibilities, it was decided to perform the mechanical deployments of MUPUS and APX and the SD2 drilling before a complete discharge of the batteries. COSAC sample analysis was preferred to Ptolemy due to lower power consumption. This reduction of power consumption should allow to have enough energy to download the science results. 


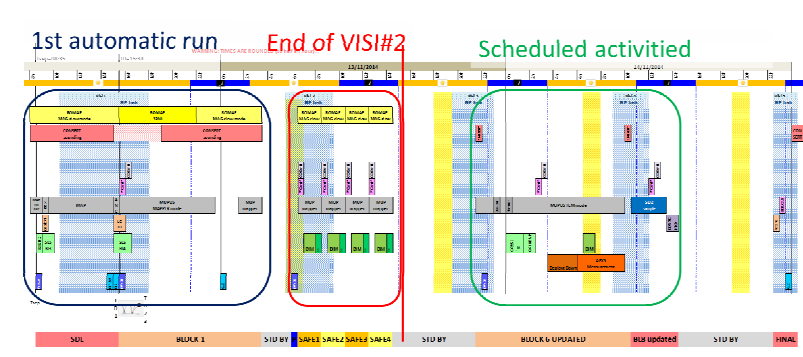

Figure 17. Scheduling of activities displayed in SONC's tool MOST (Science Operation and Navigation Centre-CNES) [4]

During the third and fourth visibilities, all science activities were successfully realised. After including last telemetry and a power consumption prediction, simulations confirmed that the lander could be supplied by the batteries system until the fifth (last) visibility.

Indeed, during the fifth and last visibility, the bus voltage reached $20.3 \mathrm{~V}$ which corresponds to the minimum bus voltage before switch-off. Nevertheless, all science activities were realised during SDL/FSS. The batteries system operated as expected despite low temperatures and power peaks.

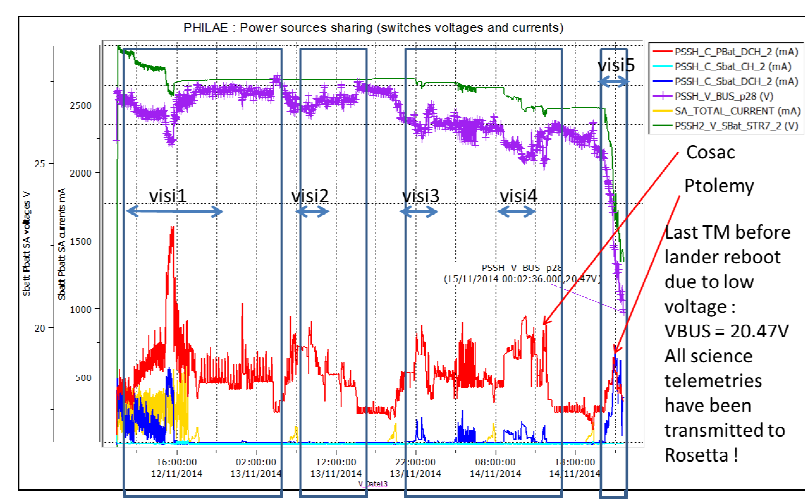

Figure 18. Batteries system telemetry from the beginning to the end of SDL/FSS (green : secondary battery voltage, purple : bus voltage, red : primary battery current, blue : secondary battery discharge current, yellow: total solar arrays current)

Telemetry and final simulations were compared in order to evaluate the model. Some discrepancies can be seen as illustrated in Figure 19. Some hypotheses were considered:

- Difficulty to evaluate the real capacity of secondary battery in flight

- Degradations of primary battery on flight slightly more important than the ageing defined on ground

- Approximation of harness resistances, voltage drop of diodes between batteries and bus bar

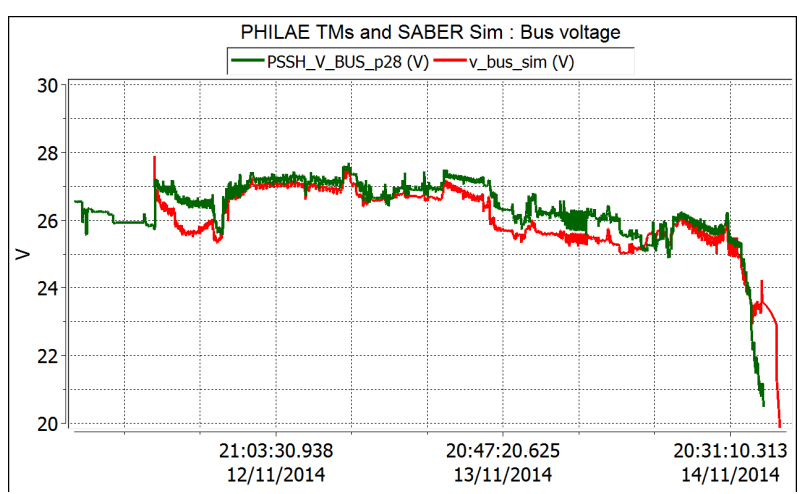

Figure 19. Telemetries and simulation results comparison on bus voltage

\subsection{LTS}

After the SDL and FSS activities, Philae switched to wake-up mode. Some thermal and power conditions had to be fulfilled in order for Philae to wake up.

In mid-June 2015, a first contact between Rosetta and Philae occurred. The telemetry of the secondary battery voltage indicated that the battery was charged (SoC around $86 \%$ ) despite the cold temperature of charge (from $0^{\circ} \mathrm{C}$ ). From the extrapolations of charge current telemetry, the secondary battery energy was estimated, by simulation, at $75 \mathrm{Wh}$. According to these elements, the secondary battery seemed in good health. Nevertheless, due to the following sporadic RF contacts and the uncertainties in lander health, it was not possible to re-activate any payloads during LTS.

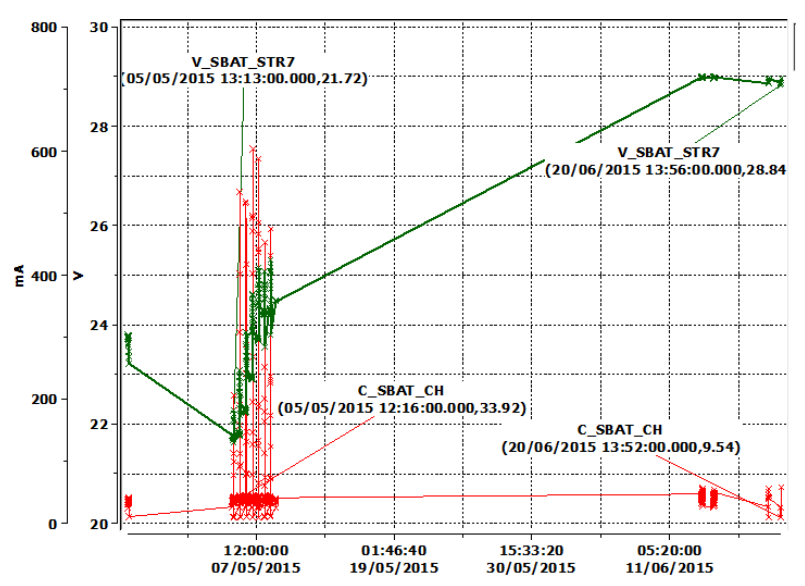

Figure 20. Last telemetry of secondary battery voltage

\section{CONCLUSION}

Philae achieved its objectives. All the science activities were realised. The design of the batteries system allowed an efficient monitoring and good performance. The storage strategy and the different ground tests have proven useful for preparation of operations. The developed model was integrated into the operational loop. It helped with the operations strategy and 
decisions, particularly during SDL and FSS. The batteries system ensured this mission.

\section{REFERENCES}

1. Ulamec S., Balazs A., Biele J., Espinasse S., Fantinati C., Fischer H.-H., Fischer H., Flamini E., Fronton J.-F., Gaudon P., Geurts K., Hilchenbach M., Jansen S., Kletzkine P., Krause C., Küchemann O., Maibaum M., Melac L., Pätz B., Peragin E., Roll R., Sangiovanni G., Sous S., Tropolle E., Warmbold G., Wiillnecker R., Rosetta Lander - System Status after five years in Space,

2. S.Ulamec et al , Rosetta Lander - Landing and operations on comet 67P/ChuryumovGerasimenko, Acta Astronautica, j.actaastro.2015.12.050

3. Moussi A., Fronton J.-P., Gaudon P., Delmas C., Lafaille V., Jurado E., Durand J., Hallouard J., Mangeret M., Charpentier A., Ulamec S., Fintinati S., Geurts K., Salatti K., Bibring J.-P., Boehnhardt H. (2015), The Philae lander: science planning and operations, Acta Astronautica, j.actaastro.2015.12.050.

4. Moussi A., Fronton J.-P., Gaudon P., Delmas C., Lafaille V., Jurado E., Durand J., Hallouard J., Mangeret M., Charpentier A., Ulamec S., Fintinati S., Geurts K., Salatti K., Bibring J.-P., Boehnhardt H. (2015), Philae: science scheduling and unknown context, lessons learned, $66^{\text {th }}$ International Astronautical Congress

5. Fredon S., Melac L., Simmons N, Long-Duration Leo Mission Experience With ABSL Batteries Onboard The Myriade SmallSAT Platform, Proceedings of the 9th European Space Power Conference, held 6-10 June 2011 at Saint Raphael, 